\title{
O PROTAGONISMO JUVENIL EM MOVIMENTOS SOCIAIS BRASILEIROS E O PAPEL DA GEOGRAFIA ESCOLAR
}

\begin{abstract}
Alcinéia de Souza Silva ${ }^{1}$
Resumo: O Brasil, nos últimos anos, vivenciou tempos históricos, marcados pelos expressivos movimentos sociais protagonizados majoritariamente por jovens, dentre os quais muitos estudantes. Neste sentido, o propósito deste trabalho é empreender algumas reflexões acerca do protagonismo juvenil nas lutas sociais brasileiras e do papel da Geografia Escolar neste contexto, de modo a destacar a sua importância e imprescindibilidade enquanto ferramenta intelectual no processo de formação crítica e cidadã do indivíduo. Como metodologia, utilizouse da apreciação discursiva de literaturas que versam sobre os movimentos sociais ocorridos no país entre os anos 2013 e 2016, bem como sobre o sentido de se ensinar e aprender Geografia, ambos ancorados em pressupostos teóricos críticos. A partir desta reflexão teórica e da análise do contexto de revelações provenientes das lutas juvenis, o trabalho propõe o desenvolvimento de uma educação geográfica na e para a cidadania, processada pelos aportes teóricometodológicos das pedagogias críticas, a exemplo da Pedagogia Histórico-Crítica, cujo olhar se direciona à compreensão e transformação das realidades sociais, contraditórias e espacialmente desiguais.
\end{abstract}

Palavras-chave: Geografia Escolar. Pedagogias críticas. Protagonismo juvenil.

\section{THE YOUTH PROTAGONISM IN BRAZILIAN SOCIAL MOVEMENTS AND THE ROLE OF SCHOOL GEOGRAPHY}

\begin{abstract}
In recent years, Brazil has experienced historical times, marked by the expressive social movements mainly carried out by young people, among whom many students. In this sense, the purpose of this work is to reflect upon youth protagonism in Brazilian social movements and the role of School Geography in this context, in order to highlight its importance and indispensability as an intellectual tool in the process of critical and citizen formation of the individual. Methodologically, this work is based on the discursive appreciation of literatures that deal with the social movements that occurred in the country between the years 2013 and 2016, as well as with the meaning of teaching and learning Geography, both anchored in critical theoretical assumptions. The work proposes the development of a geographical education in and for citizenship, processed by the theoretical-methodological contributions of critical pedagogies, such as the Historical-Critical Pedagogy, whose aim is directed to the understanding and transformation of social realities, contradictory and spatially unequal.
\end{abstract}

Keywords: School Geography. Critical Pedagogies. Youth Protagonism.

\section{INTRODUÇÃO}

Primeiramente, destaca-se que o foco deste trabalho é abordar a formação de um indivíduo crítico, que se posiciona histórica e socialmente por meio de uma formação

\footnotetext{
${ }^{1}$ Doutoranda e Mestra em Geografia pela Universidade de Brasília (UnB) na área de concentração em Gestão Territorial e Ambiental. Professora da Secretaria Municipal de Educação de Formosa-GO. Integra o grupo de pesquisa - Ensino, Aprendizagem e Formação de Professores em Geografia da Universidade de Brasília - GEAF/UnB. E-mail: alcineia_s@yahoo.com.br
} 


\section{REVISTA ELETRÔNICA \\ DA GRADUAÇÃO/PÓS-GRADUAÇÃO EM EDUCAÇÃO UFG/REJ}

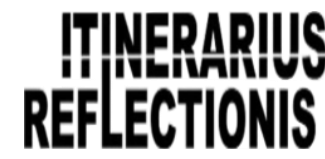

ISSN. 1807-9342

Volume 14, N. 2, 2018

política, tendo como base a Geografia. Em segundo lugar, evidenciamos que o que nos levou a defender a importância e singularidade da Geografia Escolar na formação crítica e reflexiva do aluno enquanto sujeito social é o fato dela propiciar a compreensão do modo como os fatos sociais refletem na (re)organização, acesso e uso dos espaços, conforme têm sido efetivados pelos jovens estudantes nas lutas sociais brasileiras.

Os fatores que motivam nossos escritos se estruturam em dois eixos principais, o primeiro dos quais se fundamenta no fato de os expressivos movimentos sociais ocorridos no Brasil nos últimos anos revelarem a necessidade de se pensar sobre o papel da escola na formação dos jovens que protagonizam esses movimentos; e o segundo, no fato de a maciça participação da juventude nessas lutas em combate aos processos de desigualdades, injustiças e de políticas que intensificam tais condições revelar, ainda, um considerável perfil político destes sujeitos, junto à capacidade de ler e interpretar criticamente as objeções sociais instaladas no país.

Objetiva-se, assim, empreender reflexões acerca do protagonismo juvenil nas lutas sociais brasileiras dos últimos cinco anos e do papel da Geografia Escolar neste contexto, de modo a destacar a sua importância e imprescindibilidade, enquanto ferramenta intelectual no processo de formação crítica e cidadã do indivíduo. Argumenta-se que tal processo pode ser propiciado pela adequada mediação pedagógica (crítica) dos conteúdos geográficos, que se configuram como fontes primordiais à instrumentalização cognitiva do estudante, e, logo, à sua formação política, ao oportunizar a interpretação da organização social dos lugares pela ótica de sua dimensão espacial (que é também social).

A relação que aqui estabelecemos entre o ensino de Geografia e o contexto de manifestações sociais, no qual se inscreve o protagonismo juvenil, se deve à compreensão de que as contradições engendradas socialmente se manifestam no espaço, de uma forma ou de outra, afetando a localização, distribuição e diferenciação dos sujeitos e das coisas. Tendo como objeto de estudo o espaço geográfico, entende-se que a Geografia, ao permitir que o aluno compreenda as relações indissociáveis entre o homem e o meio, bem como que reconheça o espaço como uma feitura social, possibilita a leitura da complexa realidade social e suas manifestações espaciais, de modo a contribuir para sua formação política. 


\section{REVISTA ELETRÔNICA \\ DA GRADUAÇÃO/PÓS-GRADUAÇÃO EM EDUCAÇÃO UFG/REJ}

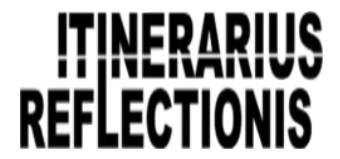

ISSN. 1807-9342

Volume 14, N. 2, 2018

Nesse sentido, a escola, ao ensinar Geografia, deve propiciar meios para que os alunos desenvolvam a capacidade de analisar criticamente os aspectos socioeconômicos, políticos, culturais, e ambientais de uma sociedade, bem como perceber que os fatos e fenômenos que se relacionam a esses aspectos se exprimem no espaço. Isso indubitavelmente levará o aluno a refletir sobre: quem sou eu nesse espaço, qual a minha condição no processo de sua construção, de que modo determinada medida ou acontecimento interferem na organização espacial em que vivo e para além dele?

A partir desses argumentos, e pautados na metodologia que se centra na apreciação das literaturas já existentes acerca dos assuntos aqui abordados, desenvolveremos uma discussão relativa ao protagonismo juvenil nos principais movimentos sociais que eclodiram no Brasil entre os anos de 2013 e 2016, de forma a se pensar a função da escola, de modo geral, e da Geografia, de modo particular, frente ao quadro de tensões instaladas no país, que se traduzem em contextos de difícil democracia brasileira.

Dado o exposto, defenderemos, por fim, o desenvolvimento de uma Geografia Escolar na/e para a cidadania, isto é, uma Geografia Escolar com finalidades sociopolíticas. Para tanto, propomos a utilização de pedagogias com perspectivas críticas, pois partimos do pressuposto de que é possível, através da problematização da realidade social em que vivem os alunos, prepará-los para a leitura reflexiva da produção social do espaço, de maneira que possam compreendê-la e, se possível, transformá-la.

\section{O PROTAGONISMO JUVENIL EM MOVIMENTOS SOCIAIS NO BRASIL: um recorte a partir do ano 2013}

O processo de construção da história da humanidade, em função das diferenças e da pluralidade que marcam os povos, espaços e tempos, de maneira geral, consolida-se a partir de constantes lutas e enfrentamentos entre os diversos grupos sociais. Pode-se evidenciar que as discrepâncias econômicas, políticas, culturais, étnicas e sociais se configuram como a mola propulsora para estas lutas e protestos, que se manifestam principalmente em épocas de crises, e de quadros sociais em que as políticas desenvolvidas propagam as injustiças e intensificam as desigualdades. 


\section{REVISTA ELETRÔNICA \\ DA GRADUAÇÃO/PÓS-GRADUAÇÃO EM EDUCAÇÃO UFG/REJ}

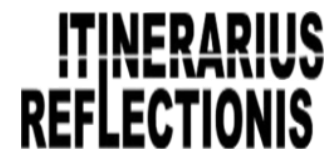

ISSN. 1807-9342

Volume 14, N. 2, 2018

Para o escopo deste trabalho, considera-se a crise do ano 2008 e o inevitável ataque ao sistema financeiro mundial como a variável elementar para a forte onda de movimentos sociais ocorrida, sobretudo a partir do ano 2011, em escala global. Naquela conjuntura, visando a contenção de uma recessão econômica, foram implantadas certas medidas políticas, como os subsídios empresariais concedidos pelo Estado e a significativa redução de gastos públicos em diversos setores sociais, que foram expressamente repudiadas pelas sociedades, inclusive por muitos jovens, por meio de protestos e manifestações, nos quais bandeiras foram erguidas em sinal de revolta e indignação contra o caráter intensificador das desigualdades já existentes que tais medidas apresentavam. Tal indignação ecoa as palavras de Santos (2011, p. A3), segundo quem "o modelo social e político tem recursos para resgatar bancos e não os tem para resgatar a juventude de uma vida sem esperanças, do pesadelo de uma educação cada vez mais cara e mais irrelevante".

Esse quadro de instabilidades eclode, no Brasil, a partir do ano 2013, quando intensivos movimentos sociais (principalmente as Jornadas de junho) emergem em diversas partes do país, expressando insatisfação com o sistema político e ações governamentais específicas. Segundo Gohn (2014, p. 20, acréscimos nossos), as lutas juvenis desse período revelaram "o desencanto com a política, a indignação diante do cenário de corrupção, falta de ética, mau uso do dinheiro e má qualidade dos serviços públicos, além da falta de vontade política dos dirigentes”. Na ocasião, viu-se milhares de jovens ecoando suas vozes em luta por um Brasil melhor, seja na política, segurança, educação, no transporte público e nas condições de vida do brasileiro.

No ano 2015, ocorre outro movimento de grande impacto e ramificação pelo território brasileiro. Trata-se das ocupações de escolas protagonizadas exclusivamente por jovens estudantes (principalmente os do Ensino Médio), cuja pauta de reinvindicações centrou-se na defesa da escola pública, gratuita e de qualidade. O motivo que os levou a se apropriarem do espaço escolar (ocupado) e a geri-lo, principalmente a partir do ano 2016, foram medidas que, segundo eles, intensificam o processo de desigualdades sociais, dentre as quais listamos as principais:

- a reforma do Ensino Médio; 


\section{REVISTA ELETRÔNICA}

DA GRADUAÇÃO/PÓS-GRADUAÇÃO EM EDUCAÇÃO

UFG/REJ

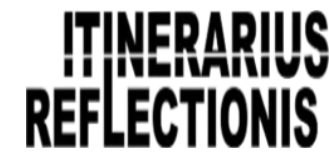

ISSN. 1807-9342

Volume 14, N. 2, 2018

- a instituição de novo regime físcal com vigência de 20 exercícios financeiros, por meio de estabelecimento de limites/tetos individualizados para as despesas primárias públicas;

- a escola sem partido, cuja proposta destaca a proibição, em sala de aula, de "práticas de doutrinação política e ideológica, bem como a veiculação de conteúdos ou a realização de atividades que possam estar em conflito com as convicções religiosas ou morais dos pais ou responsáveis pelos estudantes” (BRASIL, 2015);

- a privatização da gestão de escolas públicas;

- as condições precárias das infraestruturas das escolas; dentre outras demandas que impactam na precarização da educação pública, num todo.

Ao discorrer sobre as ocupações de escolas, Gohn (2017, p. 102) destaca que os estudantes são atores políticos relevantes na história do Brasil, e que "as ocupações [...] demonstram que os jovens dessa faixa etária querem participar, têm consciência das condições que vivem nas escolas e de outras a que têm direito". Para ela e para nós, desde o ano 2013, as ruas e as escolas se transformaram em territórios de cidadania na busca do jovem por mudanças e democracia.

No ano 2016, além da continuidade das ocupações dos estabelecimentos de ensino, que chegaram a atingir, segundo a União Brasileira dos Estudantes Secundaristas, aproximadamente 1.100 unidades ocupadas, destacamos ainda a luta social no contexto do processo de impeachment da ex-presidenta Dilma Vana Rousseff, expressa por imensa multidão de pessoas que ocuparam as ruas de diversas cidades brasileiras, seja apontando novos rumos para o país, seja em defesa do prosseguimento da forma política vigente na época. Tal processo resultou, em nossa ótica, num verdadeiro ataque à democracia brasileira, cuja discussão extrapola o escopo deste trabalho, mas que consideramos adequado mencionar, na medida em que simboliza uma significativa fragilização do regime democrático instituído no país, e se constitui enquanto pano de fundo para outros protesto sociais.

O protagonismo juvenil nas lutas sociais ocorridas nos últimos anos revela, por um lado, que o jovem deseja discutir, ser ouvido, participar de decisões de modo a 


\section{REVISTA ELETRÔNICA \\ DA GRADUAÇÃO/PÓS-GRADUAÇÃO EM EDUCAÇÃO UFG/REJ}

\section{TTEERPUS REFLECTIONIS}

ISSN. 1807-9342

Volume 14, N. 2, 2018

construir um país com menos desigualdades e opressão; ele demonstra possuir conhecimentos e interesse sobre economia, cultura, educação e política, e, por isso, questiona medidas que implicam na intensificação de problemas que essas áreas já apresentam. Por outro lado, tal protagonismo provoca reflexões de questões elementares ao processo de ensinar e aprender no âmbito da Educação Básica, quais sejam, o perfil político do jovem aluno da atualidade, a sua busca por participação nos processos decisórios, a sua vontade de mudar o país, a sua capacidade de leitura crítica da realidade social e autonomia, dentre outras.

Com isto, torna-se necessário reconhecer que a escola (e aqui se insere a Geografia) precisa se reorganizar, se reestruturar e redefinir seus projetos/papéis, discursos e suas ações, pois as práticas e características destes sujeitos escolares demandam novas dimensões formativas (não tradicionais), sobretudo pela perspectiva crítica de ensino.

\section{GEOGRAFIA ESCOLAR E CIDADANIA}

Iniciemos a seção considerando a seguinte fala de Santos (2014a, p. 22): “a cidadania, sem dúvida, se aprende". Por essa premissa, compreende-se que o cidadão se constitui, ao longo do seu processo formativo, por meio de práticas intencionais que o conduzem à leitura, interpretação e, consequentemente, à participação (ou tentativa de participação) da sociedade em que se insere. Nesse sentido, pensar as funções da Geografia, principalmente neste contexto de expressivos movimentos sociais no país e no mundo, implica refletir sobre os saberes dos quais os estudantes necessitam apropriar-se para a construção da cidadania, compreendida como "a participação política e coletiva das pessoas nos destinos da sociedade" (CAVALCANTI, 2012, p. 46).

Sobre a importância da Geografia, seja enquanto ciência ou disciplina escolar, Pontuschka, Paganelli e Cacete (2009) elucidam que:

[...] a Geografia como ciência humana pesquisa o espaço produzido pelas sociedades humanas, considerando-o como resultado do movimento de uma sociedade em suas contradições e nas relações estabelecidas entre os grupos sociais e a natureza em diversos tempos históricos. A Geografia, como disciplina escolar, oferece sua contribuição para que alunos e professores enriqueçam suas 


\section{REVISTA ELETRÔNICA \\ DA GRADUAÇÃO/PÓS-GRADUAÇÃO EM EDUCAÇÃO UFG/REJ}

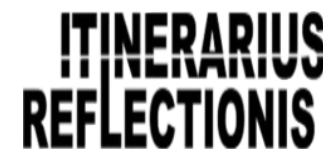

ISSN. 1807-9342

Volume 14, N. 2, 2018

representações sociais e seu conhecimento sobre as múltiplas dimensões da realidade social, natural e histórica, entendendo melhor o mundo em seu processo ininterrupto de transformação, o momento atual da chamada mundialização da economia (PONTUSCHKA, PAGANELLI e CACETE, 2009, p. 37-38).

Se o objeto de estudo da Geografia é, portanto, o espaço, constituído enquanto produção social e lócus em que se manifestam os fatos/fenômenos, salientamos que, por sua natureza, que se revela em estreita relação com a cidadania, a Geografia fornece elementos para que a leitura e a intervenção socioespacial se concretizem.

Tanto no âmbito escolar, por meio dos seus conteúdos, conceitos e temas, quanto pelos aportes teórico-metodológicos que a ciência geográfica possui, ela torna possível, ao aluno, a compreensão do mundo, na medida em que seu estudo permite o reconhecimento do espaço como um elemento precípuo às relações e organizações sociais. Isso porque (o espaço) é "formado por um conjunto indissociável, solidário e também contraditório, de sistemas de objetos e sistemas de ações, não considerados isoladamente, mas como o quadro único no qual a história se dá" (SANTOS, 2014b, p. $63)$.

Também nesse sentido, Richard Hartshorne (1939) enfatiza que a Geografia é essencial para a compreensão total da realidade, constituindo-se, assim, enquanto ferramenta necessária e indispensável à formação cidadã. Entretanto, Ruy Moreira (2009) alerta que a Geografia que desaliena é a mesma que aliena, a depender do modo como se aborda, desenvolve e interpreta seus assuntos/conteúdos. Na escola, se adequadamente (perspectiva crítica) desenvolvida pelo professor e compreendida de forma significativa pelo aluno, instrumentaliza, capacita e qualifica-o para a participação política. Callai (2013) corrobora essas ideias ao pontuar que:

[...] o entrelaçamento do discurso da ciência, do discurso da Geografia escolar e a dimensão pedagógica, que está neles embutido, permite o encaminhamento da educação geográfica. A tarefa de fazer a educação geográfica supõe desenvolver o pensamento espacial e trabalhar com os conceitos de modo que eles sejam significativos para desencadear as aprendizagens, sobretudo orientadas à construção da cidadania (CALLAI, 2013, p. 18, acréscimos nossos).

Sobre a construção de conceitos e a formação cognitiva no processo de ensinoaprendizagem, Castellar e Vilhena (2011) preconizam que a apropriação de conceitos 


\section{REVISTA ELETRÔNICA \\ DA GRADUAÇÃO/PÓS-GRADUAÇÃO EM EDUCAÇÃO UFG/REJ}

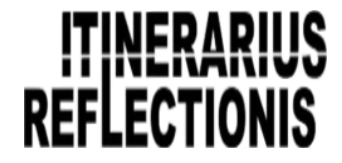

ISSN. 1807-9342

Volume 14, N. 2, 2018

torna a aprendizagem significativa, na medida em que o aluno consegue atribuir significado aos fenômenos cotidianos. Para as autoras, no ensino de Geografia, a construção de tais significados favorece a interpretação ou explicação do mundo, já que a abstração (domínio dos conceitos) é um processo fundamental para o desenvolvimento do raciocínio espacial. Essa discussão se aproxima da abordagem de Vlach (2007), que destaca que os conteúdos geográficos são decisivos para a compreensão dos problemas do mundo contemporâneo - muitos dos quais estão ligados à convivência social no seu sentido mais amplo, a partir do reconhecimento dos modos em que se reproduzem espacialmente.

Com este debate, não significa que defendemos um ensino de Geografia preso a conceitos reinantes e petrificados, mas que leve em conta a necessidade intelectual do aluno em dominar seus temas e conteúdos para a compreensão do mundo, que está em constante processo de mudanças, cujas causas são complexas e resultam do entrecruzamento de inúmeros fatores que variam de acordo com a escala geográfica e determinações políticas, culturais, socioeconômicas e até mesmo ambientais. Em virtude disso, a Geografia Escolar deve contribuir para a construção da cidadania plena do aluno (VESENTINI, 2013) enquanto sujeito social, levando-o a refletir sobre o modo como espacialmente se reproduzem/manifestam os fatos sociais, assim como sobre sua participação/condição na produção, acesso e uso dos lugares.

\section{O ENSINO DE GEOGRAFIA À LUZ DOS MOVIMENTOS SOCIAIS: por uma}

\section{Geografia na e para a cidadania}

Sublinhar a efetiva participação dos jovens e estudantes nos movimentos sociais é provocar uma reflexão sobre o papel da escola e das práticas de ensino por ela desenvolvidas. Nesse cenário, a Educação Básica, notadamente a sua última etapa (Ensino Médio), nível em que se encontram/encontravam matriculados a maioria desses jovens partícipes dos protestos, ocupa uma posição elementar em seus processos de formação. Considerar que esses estudantes, protagonistas das manifestações sociais, já possuem conhecimento consciente acerca da cidadania (ou ao menos demonstraram possuí-lo), assim como já a praticam ao lutar por seus direitos, é fundamental para o fazer pedagógico no âmbito escolar. Afinal, esses conhecimentos e experimentos 


\section{REVISTA ELETRÔNICA \\ DA GRADUAÇÃO/PÓS-GRADUAÇÃO EM EDUCAÇÃO UFG/REJ}

\section{ITINEPRARIIUS REFLECTIONIS}

ISSN. 1807-9342

Volume 14, N. 2, 2018

produzidos pelos estudantes se configuram tanto como o ponto de partida como o de chegada no processo de ensino-aprendizagem em Geografia.

Quando se afirma que a experiência social ou as práticas políticas destes jovens constituem as bases e o fim do processo educativo da escola, afirma-se que a educação deve se dar na/e para a cidadania:

$\mathrm{Na}$ cidadania, porque alguns dos jovens já desenvolvem práticas cidadãs em seu cotidiano - mesmo porque o próprio contexto de crise brasileira exige isso -, e para a cidadania, para que esses que já a praticam possam alargá-la, e para que os que se encontram alheios sejam instrumentalizados para exercê-la (SILVA, 2017, p. 133).

Pensar sobre a função da escola neste contexto, em que os jovens protagonizam as lutas sociais no intento de participar da construção e definição de novos rumos ao nosso país, e de denunciar as injustiças e formas de políticas governamentais intensificadoras do processo de desigualdade, implica também refletir acerca da função da Geografia, de modo particular, na transformação destas realidades.

Assim, propomos o desenvolvimento de práticas educativas que se ancoram na perspectiva crítica de ensino, as quais julgamos adequadas na medida em que a mediação dos conteúdos geográficos propicia a formação cidadã (na e para a cidadania), pois à Geografia no âmbito escolar cumpre

[...] empreender significativos esforços para questionar o sentido mais restrito de cidadania e promover situações que possibilitem o desenvolvimento da consciência crítica dos alunos sobre a sua realidade social, sobre seu direito a condições mais dignas de sobrevivência, direito às suas manifestações culturais, sobre o direito de acesso ao conhecimento e aos espaços da cidade (CAVALCANTI e VANILTON, 2014, p. 6).

O cerne do trabalho docente deve estar direcionado às condições e às realidades em que vivem os alunos. São realidades múltiplas, é fato, mas as pedagogias desenvolvidas devem propiciar a análise crítica e a problematização das diferentes formas de existências e vivências, de modo a conduzir os estudantes a refletir sobre as suas condições no processo de construção das suas sociedades. Como bem discutem Cavalcanti e Vanilton (2014), a relação do sujeito com a sociedade e com o espaço é mediada também pelos seus conhecimentos e percepções sobre esse espaço e a 


\section{REVISTA ELETRÔNICA \\ DA GRADUAÇÃO/PÓS-GRADUAÇÃO EM EDUCAÇÃO UFG/REJ}

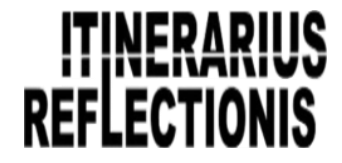

ISSN. 1807-9342

Volume 14, N. 2, 2018

sociedade. Dessa forma, um dos objetivos do ensino de Geografia na Educação Básica é contribuir para a construção da cidadania.

Nessa perspectiva, o reconhecimento do potencial de uma geografia cidadã justifica a recomendação de práticas de ensino pautadas nas pedagogias de cunho crítico, a exemplo da vertente idealizada por Demerval Saviani (2008), conhecida como histórico-crítica. Ancorada na prática educativa questionadora, reflexiva e emancipadora, seu propósito é comprometer-se com a transformação social. Com base nisso, Batista e Lima (2012) afirmam que trata-se de uma pedagogia articulada com a prática social transformadora, isto é, aquela que possibilita o desenvolvimento do aluno direcionado à construção de um mundo mais justo, solidário, coletivo, democrático.

Ao discorrer sobre o assunto, Saviani (2008) preconiza que escola e sociedade devem ser articuladas, pois, levando em consideração que a sociedade em que vivemos é dividida em classes/grupos com interesses opostos, é necessário que a escola desenvolva práticas problematizadoras das ações/relações sociais que impedem a construção de uma sociedade menos desigual. Para o autor, a finalidade da educação não deve ser outra senão a cidadania. Para isso, portanto, ela deve preparar o indivíduo para que este seja capaz de participar ativamente da construção e dos processos decisórios da sociedade em que vive, bem como de decifrar e desenvolver ações interventivas frente a situações contraditórias, próprias do mundo globalizado.

Na aurora do século XXI, em que as diferenças e desigualdades se evidenciam, sobretudo pelo modo hegemônico de relação e organização capitalistas, é inevitável que a contestação/revolta/indignação social aflore. Logo, cumpre, à Geografia, auxiliar o aluno a desenvolver raciocínio capaz de compreender a realidade social contemporânea à luz de sua base espacial, e de nela intervir. As práticas de ensino no bojo da educação geográfica devem, portanto, procurar romper com o tradicionalismo, já arraigado há séculos nas escolas básicas, e primar pelas pedagogias que favoreçam o desenvolvimento da autonomia, criatividade, criticidade, cidadania, liberdade e desalienação do sujeito. O contexto de difícil democracia vivenciado no Brasil é bastante propício para isso.

Não obstante, é necessário esclarecer que não se condena, aqui, a pedagogia tradicional, pois ela possui mecanismos positivos para o processo de ensinoaprendizagem. Mas, considera-se que, por si só, sem a incorporação de outros métodos 


\section{REVISTA ELETRÔNICA \\ DA GRADUAÇÃO/PÓS-GRADUAÇÃO EM EDUCAÇÃO UFG/REJ}

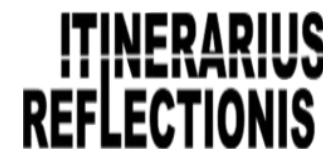

ISSN. 1807-9342

Volume 14, N. 2, 2018

pedagógicos, os quais propiciem ao aluno espaços de diálogo, problematização e criticidade, ela impõe diversas barreiras ao processo de desenvolvimento humano e cognitivo do educando, e, consequentemente, à formação crítica e cidadã do sujeito.

\section{CONSIDERAÇÕES FINAIS}

Em vista dos argumentos apresentados, torna-se mister sublinhar que a Geografia, por propiciar a leitura crítica da realidade social, constitui-se uma poderosa ferramenta intelectual à construção da cidadania, notadamente diante do quadro de tensões instaladas no Brasil nos últimos anos. O expressivo protagonismo juvenil evidenciado nos processos de lutas em prol da efetivação da democracia e de mudanças nos âmbitos político, educacional e socioeconômico do país configura-se como pano de fundo para se refletir acerca dos desafios da escola contemporânea, que não são poucos. Afinal, o papel que ela deve assumir é o de uma posição primária na instrumentalização deste sujeito, que, ao participar dos movimentos sociais, revela que se fazem necessários tanto novos modelos de sociedade e de se fazer política, quanto novas organizações, práticas e projetos escolares.

Nesse sentido, concerne, às práticas de ensino, notadamente às de Geografia, a apropriação das potencialidades oferecidas pelas pedagogias críticas, no intuito de desencadear ou aprimorar nos estudantes os saberes necessários às práticas cidadãs. É iniludível que à Geografia Escolar cumpre, por excelência, o papel de decifrar o espaço, lócus da materialização dos fatos/fenômenos sociais. Propiciar espaços para uma leitura reflexiva acerca do mundo e das complexidades que o constituem, a partir da adequada prática, didatização/mediação do professor, é, assim, pilar imprescindível para a formação cidadã do indivíduo.

Por fim, desinteressar-se pelo conhecimento do espaço, da sua dialética e dos seus movimentos implica contribuir para a construção de sociedades mais alienadas, oprimidas e altamente desiguais. Defendemos, ao contrário, a existência e o fortalecimento da Geografia Escolar voltada à formação na e para a cidadania, o que demanda práticas de ensino orientadas ao desenvolvimento de práticas sociais transformadoras, a partir da inserção, do pertencimento e da participação do sujeito na construção de sociedades menos opressoras e excludentes. 
REVISTA ELETRÔNICA

DA GRADUAÇÃ̃/PÓS-GRADUAÇÃO EM EDUCAÇÃO

UFG/REJ

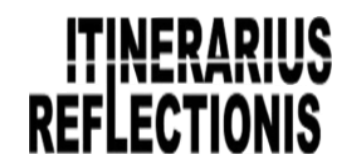

ISSN. 1807-9342

Volume 14, N. 2, 2018

\section{REFERÊNCIAS}

BATISTA, Eraldo Leme; LIMA, Marcos Roberto. A pedagogia histórico-crítica como teoria pedagógica transformadora - da consciência filosófica à prática revolucionária. In: MARSIGLIA, Ana Carolina Galvão; BATISTA, Eraldo Leme. Pedagogia histórico-crítica: desafios e perspectivas para uma educação transformadora. Campinas, São Paulo: Autores Associados, 2012.

BRASIL. Projeto de Lei n. ${ }^{\mathbf{0}} \mathbf{8 6 7}$, de 2015. Disponível em: http://www.camara.gov.br/sileg/integras/1317168.pdf. Acesso em 11 dez. 2016.

CALLAI, Helena Copetti. A formação do profissional da geografia: o professor. Injuí: Ed. Unijuí, 2013.

CASTELLAR, Sônia; VILHENA, Jerusa. Ensino de Geografia. São Paulo: Cengage Learning, 2011. Coleção Ideias em ação/ Coordenadora Anna Maria Pessoa de Carvalho.

CAVALCANTI, Lana de Souza. O ensino de Geografia na escola. Campinas, São Paulo: Papirus, 2012.

CAVAlCANTI, Lana de Souza; VANILTON, Camilo de Souza. A formação do professor de Geografia para atuar na educação cidadã. In: XII Colóquio Internacional de Geografia. Barcelona, 2014.

GOHN, Maria da Glória. Sociologia dos movimentos sociais. $2^{\mathrm{a}}$ ed. São Paulo: Cortez, 2014.

. Manifestações e protestos no Brasil: correntes e contracorrentes na atualidade. São Paulo: Cortez, 2017.

HARTSHORNE, Richard. The Nature of Geography. Annals of Association of American Geographers, Lancaster, Pennsylvania, v. 29, n. 3-4, 1939.

MOREIRA, Ruy. O que é Geografia. 2. ed. São Paulo: Brasiliense, 2009.

PONTUSCHKA, Nídia Nacib; PAGANELLI, Tomoko Iyda; CACETE, Núria Hanglei Cacete. Para ensinar e aprender Geografia. $3^{\text {a }}$ ed. São Paulo: Cortez, 2009.

SANTOS, Boaventura de Souza. O caos da desordem. Folha de São Paulo, 16 ago. 2011, caderno Opinião, p. A3.

SANTOS, Milton. O espaço do cidadão. 7. ed. São Paulo: Editora da Universidade de São Paulo, 2014a.

A natureza do espaço: Técnica e tempo, Razão e Emoção. $4^{\mathrm{a}}$ ed. São Paulo:

Editora da Universidade de São Paulo, 2014b. 
REVISTA ELETRÔNICA

DA GRADUAÇÃO/PÓS-GRADUAÇÃO EM EDUCAÇÃO

UFG/REJ

SAVIANI, Demerval. Escola e democracia. Campinas, São Paulo: Autores associados. 2008.

SILVA, Alcinéia de Souza. Juventudes e movimento de ocupação das escolas: caminhos e desafios para o ensino de Geografia. Dissertação de Mestrado.

Departamento de Geografia. Universidade de Brasília (UnB), Brasília-DF, 2017. 161p.

VESENTINI, José William (org.). O ensino de Geografia no século XXI. $7^{\text {a }}$ ed. Campinas, SP: Papirus, 2013.

VLACH, Vânia. Papel do ensino de Geografia na compreensão de problemas do mundo atual. Scripta Nova - Revista electrónica de Geografía y ciencias sociales. Barcelona, vol. XI, núm. 245 (63), 1 de ago. 2007.

WALLERSTEIN, Immanuel. A esquerda mundial após 2011. In: HARVEY, David [et al.]. Occupy: movimentos de protestos que tomaram as ruas. São Paulo: Boitempo: Carta maior, 2012. 